\title{
Economic evaluation of conditional cash transfer scheme for postponement of first pregnancy in newly married couples in Satara district of Maharashtra (India)
}

Asha K. Pratinidhi, Swapnil V. Lale ${ }^{1}$

Director of Research, KIMS Deemed University, Karad, ${ }^{1}$ Additional District Health Officer (Family welfare), Zilla Parishad,

Satara, Maharashtra, India

Address for the Correspondence:

Dr. Swapnil V. Lale, A-4, Chintamani Vaibhav Apartment, Near Sanjeevan Hospital, Sadar Bazar, Satara - 415 002,

Maharashtra, India. E-mail: swsipn@gmail.com

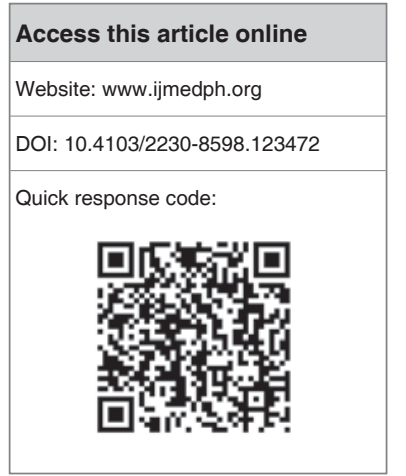

Background: Since 2007, Satara district is implementing a voluntary conditional cash transfer scheme named "Second Honeymoon Package" (SHP) for postponement of first pregnancy. This study was undertaken to evaluate it's effectiveness in preventing pregnancies, utilizing the years for learning or betterment in jobs. Cost-effectiveness analysis was undertaken from government's viewpoint and that from beneficiary's viewpoint. Objectives: To perform the economic evaluation of second honeymoon package programme from the perspective of beneficiaries and that of Government of Maharashtra during the defined time horizon. To determine the targets to be achieved so as to make the programme cost- effective. Materials and Methods: This was an evaluation study of a community based interventional programme. This study employed quasi-experimental study design. Economic evaluation was conducted from the perspective of Government of Maharashtra and that of beneficiaries'. Costs and consequences SHP were evaluated in comparison with those of routine family welfare programme. Sensitivity analysis was done using Treeage Pro ${ }^{\circledR}$ version 2009 software. Results: Cost for participation in programme was Rs. 965888/268 person years of productivity. Cost of not participating in the Second honeymoon programme but availing routine family planning services was Rs. 298902/133 person years gained. Rankings analysis showed that no strategies were clearly dominated by any other. Extended dominance report indicates no strategies were eliminated by extended dominance. Incremental cost-effectiveness ratio was Rs.4920/person year of productivity. Conclusions: The SHP is cost effective at high success and productivity rates. The success rate of postponement of first pregnancy was $51.4 \%$. Postponement of pregnancy by 2 years provides $45 \%$ chances of productive utilization of time.

Key words: Decision analytic modeling, incremental cost effectiveness ratio, second honeymoon package

\section{INTRODUCTION}

Since 2007, Satara district is implementing a pilot project; a voluntary conditional cash transfer scheme named "Second Honeymoon Package" (SHP) with a corpus of Rs 6 crore from the National Rural Health Mission. If couples who have married after April 2007 and registered themselves with the zilla parishad and deferred having children for two years, they were promised an incentive of Rs 5,000. Couples who opted to wait a third year would earn Rs 7,500. By the time the couple is enrolled for the benefit of postponement of first pregnancy and childbirth, their first honeymoon is already over. Their Second honeymoon would commence after the desired period of postponement of first pregnancy. Hence, the name "Second Honeymoon Package" is given to the scheme. Since this is a pilot project, there is a need of its evaluation before taking it on scale. Therefore; this study was undertaken to evaluate its effectiveness in preventing pregnancies, utilizing the years for learning or betterment in jobs. Cost-effectiveness analysis was undertaken from government's viewpoint and that from beneficiary's viewpoint. 


\section{OBJECTIVES}

1 To perform the economic evaluation of second honeymoon package programme from the perspective of beneficiaries and that of Government of Maharashtra during the defined time horizon in Satara district.

2. To determine the targets to be achieved so as to make the programme cost- effective.

\section{MATERIAL AND METHODS}

Institutional ethics committee of Krishna Institute of Medical Sciences (KIMS) Deemed University, Karad has given clearance, wide its letter dated $12^{\text {th }}$ October 2010. This was an evaluation study of a community based interventional programme. This study employed quasi-experimental study design. Sources of data includes "Second Honeymoon package" register, filled consent forms, cash books, reports, monthly tour diaries were collected and analysed. By using recall questionnaire for M.P.W./A.N.M./H.A./MO; information of their monthly salary and working hours was calculated. Information about how many days the health center was used for family planning/ Second honeymoon package programme was collected.

Information about expenditure incurred as well as economic benefit accrued was calculated from $17^{\text {th }}$ June 2010 to 16 th June 2012. Economic evaluation was conducted from the perspective of Government of Maharashtra and that of beneficiaries'. Costs and consequences SHP were evaluated in comparison with those of routine family welfare programme. Cases were the participants of Second Honeymoon package programme while the controls were the couples residing in the same village as that of participants and married in the same season or year. Data collection tool was filled up by duly trained Auxiliary nurse midwife (ANM) and Multi-purpose health workers (MPW). Separate Training sessions were held in each primary health centers by the investigator, Taluka medical officer, health supervisors from the district health office, Zilla parishad, Satara.

The resource consumption in health care sector includes contraceptive material, use of health center buildings, value of time of health workers and so on. These include not only the cost of providing the initial programme but also all the continuing care cost. (e.g. printing of forms, travelling allowance etc.) The patient and family resources consisted of out-of-pocket expenses in travelling to health centres, lost wages of beneficiaries and accompanying person. Enquiries were made about whether absence from work is required to avail the benefits of the programme. Effects include postponement of first pregnancy, productive utilization of time etc.

Uncertainties are pervasive in economic evaluations. ${ }^{[1]}$ There were four types of uncertainties. First was methodological uncertainty, this was dealt with reference case i.e. present study and sensitivity analysis. Second one was sampling variation, which was analysed with statistical methods using Stata ${ }^{\circledR}$ version 12 statistical software and appropriate tests of significance were applied. Modelling methods were used for third type of uncertainty, which was related to extrapolation of results beyond the study conditions. For that Monte Carlo simulation was performed. Sensitivity analysis takes care of fourth type of uncertainty, which was related to generalizability or transferability of results. Sensitivity analysis was done using Tree-age Pro ${ }^{\circledR}$ version 2009 software.

\section{RESULTS}

One thousand and ninety five out of one thousand three hundred and thirty five participants $(80.8 \%$ ) have used condoms, 125 participants $(9.22 \%)$ have used oral pills while only 15 participants $(1.1 \%)$ have used safe period method. Table 1 shows different

\begin{tabular}{|c|c|c|c|c|c|c|c|c|c|}
\hline \multirow[b]{2}{*}{$A$} & \multirow{2}{*}{$\begin{array}{l}\text { Costs and effects } \\
\begin{array}{l}\text { Productive utilization } \\
\text { of time }\end{array}\end{array}$} & \multicolumn{2}{|c|}{$\begin{array}{c}\text { Female participants- } \\
\text { successful postponement }\end{array}$} & \multicolumn{2}{|c|}{$\begin{array}{c}\text { Male participants- } \\
\text { successful postponement }\end{array}$} & \multicolumn{2}{|c|}{$\begin{array}{c}\text { Female participants- } \\
\text { failures }\end{array}$} & \multicolumn{2}{|c|}{$\begin{array}{l}\text { Male participants- } \\
\text { failures }\end{array}$} \\
\hline & & Yes & no & Yes & no & Yes & no & Yes & no \\
\hline $\mathrm{B}$ & No. of persons & 404 & 300 & 533 & 129 & 262 & 389 & 451 & 190 \\
\hline $\mathrm{C}$ & share in each group & $57.39 \%$ & $42.61 \%$ & $80.51 \%$ & $19.49 \%$ & $40.25 \%$ & $59.75 \%$ & $70.36 \%$ & $29.64 \%$ \\
\hline $\mathrm{D}$ & $\begin{array}{l}\text { average cost/person } \\
\text { in INR }\end{array}$ & 2533 & 2533 & 2533 & 2533 & 2533 & 2533 & 2533 & 2533 \\
\hline$E$ & $\begin{array}{l}\text { cost for this Group in } \\
\text { INR }\end{array}$ & 1023291.6 & 759890 & 1350035.7 & 326744.1 & 663619.8 & 985298.1 & 1142337.9 & 481251 \\
\hline $\mathrm{F}$ & $\begin{array}{l}\text { Cumulative person } \\
\text { years of education }\end{array}$ & 300 & 0 & 58 & 0 & 127 & 0 & 27 & 0 \\
\hline \multirow[t]{2}{*}{ G } & Additional occupation & \multicolumn{2}{|c|}{ Cumulative person years } & \multicolumn{2}{|c|}{ Cumulative person years } & \multicolumn{2}{|c|}{ Cumulative person years } & \multicolumn{2}{|c|}{ Cumulative person years } \\
\hline & & \multicolumn{8}{|c|}{ Amongst those who have utilized their time productively } \\
\hline $\mathrm{H}$ & Labourers & \multicolumn{2}{|l|}{32} & \multicolumn{2}{|l|}{150} & \multicolumn{2}{|l|}{28} & \multicolumn{2}{|l|}{147} \\
\hline I & Service & \multicolumn{2}{|l|}{40} & \multicolumn{2}{|l|}{65} & \multicolumn{2}{|l|}{23} & \multicolumn{2}{|l|}{66} \\
\hline $\mathrm{J}$ & Business & \multicolumn{2}{|l|}{48} & \multicolumn{2}{|l|}{261} & \multicolumn{2}{|l|}{30} & \multicolumn{2}{|l|}{189} \\
\hline $\mathrm{K}$ & Professional & \multicolumn{2}{|l|}{7} & \multicolumn{2}{|c|}{7} & \multicolumn{2}{|l|}{2} & \multicolumn{2}{|l|}{7} \\
\hline $\mathrm{L}$ & $\begin{array}{l}\text { Productive person } \\
\text { years }=\mathrm{F}+\mathrm{H}+\mathrm{I}+\mathrm{J}+\mathrm{K}\end{array}$ & \multicolumn{2}{|l|}{427} & \multicolumn{2}{|c|}{541} & \multicolumn{2}{|l|}{210} & \multicolumn{2}{|l|}{436} \\
\hline
\end{tabular}


sub-groups among participants according to postponement of child birth and productive utilization of time. Amongst male and female participants, some had succeeded in postponement of pregnancy while some could not. Third and fourth column dealt with successful postponement by male and female participants. Fifth and sixth column gave information about the participants who could not postpone the child birth by two or more years. Each column was again sub-divided into 2 groups according to productive utilization of time. Four hundred and four female participants had both successful postponement and productive utilization of time. Some spent 3-6 months productively while some utilized 2 or more years. Cumulative person-years of productivity in this group come to 427.

Accordingly the values for all 8 sub-groups were calculated. Now we had both the values of costs and effects. These were populated in the payoff column of the decision analysis tree, Figure 1.

Table 2 shows the sub-groups among controls according to postponement of child birth and productive utilization of time. Controls were divided into 4 groups. Two groups were made for females and males who were successful in postponing pregnancy.
Two sub-groups were for male and females who could not postpone pregnancy by at least 2 years. Each column is again subdivided into 2 , according to whether they had utilized their time productively or not. In the control group there were 131 females who had successfully postponed pregnancy and utilized their time productively. The average cost was multiplied by the number of persons in each group. Some persons could use less than 6 months productively while others utilized two or more years productively. Now the values of costs and effects were ready to be inserted in the decision analysis tree in Figure 1.

Figure 1 shows the decision tree model for this study. It is constructed using the software Treeage Pro ${ }^{\mathrm{TM}}$. From the decision node

'Marriage' two branches emanate. One branch was for those who have participated in the Second honeymoon programme and other for the controls. Each branch in turn again divided into two chance nodes $(\mathrm{O})$; first group constitutes those couples who have postponed their childbirth for more than two years. And second group could not postpone the childbirth by two years. Again each branch was subdivided into males/females. This sub branch again

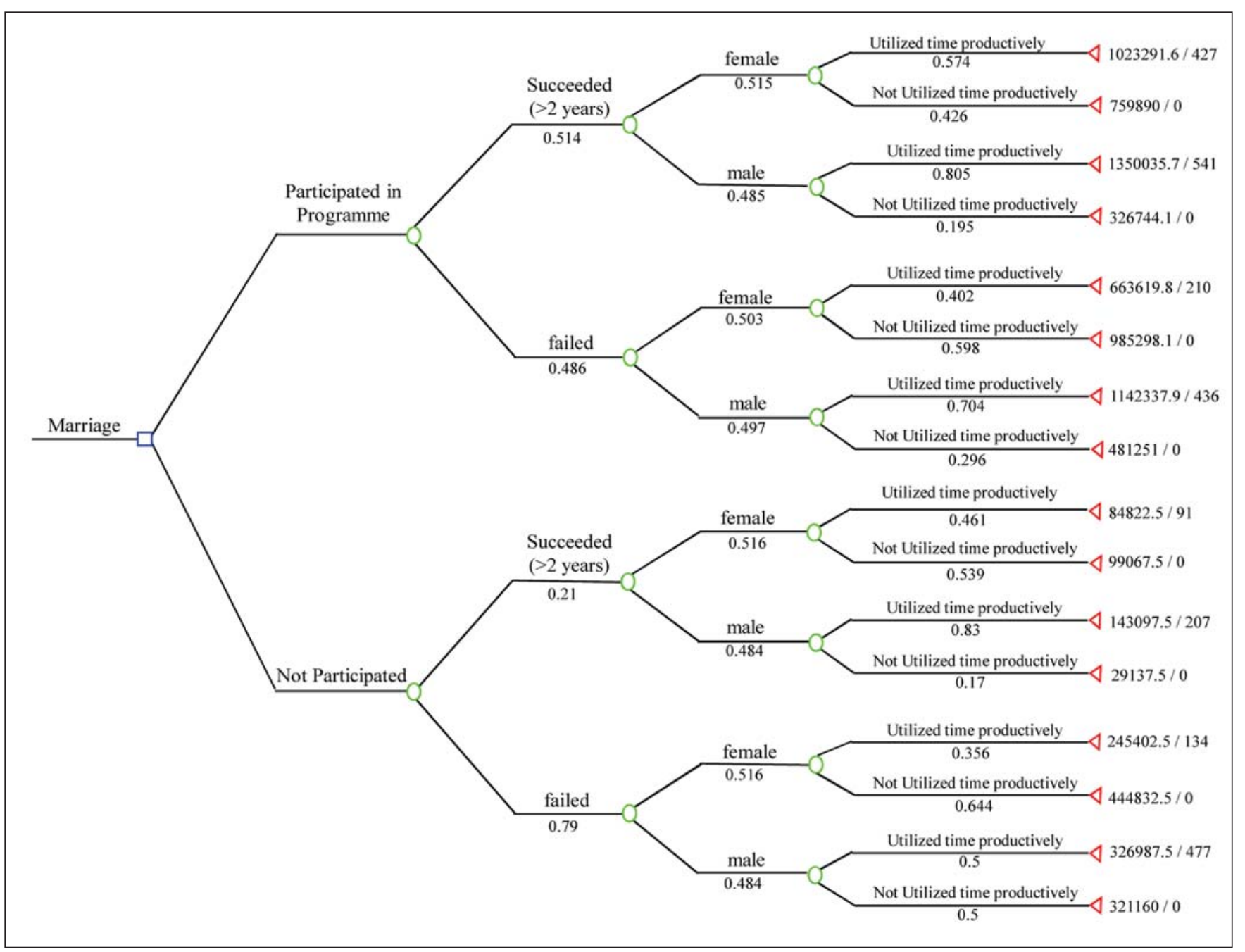

Figure 1: Decision tree 


\begin{tabular}{|c|c|c|c|c|c|c|c|c|c|}
\hline \multirow[b]{2}{*}{$A$} & \multirow{2}{*}{\begin{tabular}{l}
\multicolumn{1}{c}{ Costs and effects } \\
$\begin{array}{l}\text { Productive utilization } \\
\text { of time }\end{array}$
\end{tabular}} & \multicolumn{2}{|c|}{$\begin{array}{c}\text { Female controls with } \\
\text { successful postponement }\end{array}$} & \multicolumn{2}{|c|}{$\begin{array}{c}\text { male controls with } \\
\text { successful postponement }\end{array}$} & \multicolumn{2}{|c|}{ Female controls- failures } & \multicolumn{2}{|c|}{$\begin{array}{l}\text { Male controls- } \\
\text { failures }\end{array}$} \\
\hline & & Yes & no & Yes & no & Yes & no & Yes & no \\
\hline $\mathrm{B}$ & No. of persons & 131 & 153 & 221 & 45 & 379 & 687 & 505 & 496 \\
\hline $\mathrm{C}$ & $\begin{array}{l}\text { percentage share in } \\
\text { each group }\end{array}$ & $46.13 \%$ & $53.87 \%$ & $83 \%$ & $17 \%$ & $35.55 \%$ & $64.45 \%$ & $50 \%$ & $50 \%$ \\
\hline $\mathrm{D}$ & $\begin{array}{l}\text { average cost/person } \\
\text { in INR }\end{array}$ & 647.5 & 647.5 & 647.5 & 647.5 & 647.5 & 647.5 & 647.5 & 647.5 \\
\hline$E$ & $\begin{array}{l}\text { cost for this Group in } \\
\text { INR }\end{array}$ & 84822.5 & 99067.5 & 143097.5 & 29137.5 & 245402.5 & 444832.5 & 326987.5 & 321160 \\
\hline $\mathrm{F}$ & $\begin{array}{l}\text { Cumulative person } \\
\text { years of education }\end{array}$ & 40 & 0 & 10 & 0 & 19 & 0 & 3 & 0 \\
\hline \multirow[t]{2}{*}{ G } & Additional occupation & \multicolumn{2}{|c|}{ Cumulative person years } & \multicolumn{2}{|c|}{ Cumulative person years } & \multicolumn{2}{|c|}{ Cumulative person years } & \multicolumn{2}{|c|}{$\begin{array}{c}\text { Cumulative person } \\
\text { years }\end{array}$} \\
\hline & & \multicolumn{8}{|c|}{ Amongst those who have utilized their time productively } \\
\hline $\mathrm{H}$ & Labourers & 15 & & \multicolumn{2}{|l|}{54} & 18 & & \multicolumn{2}{|l|}{186} \\
\hline I & Service & 16 & & \multicolumn{2}{|l|}{45} & 47 & & \multicolumn{2}{|l|}{75} \\
\hline $\mathrm{J}$ & Business & 20 & & \multicolumn{2}{|l|}{98} & 50 & & \multicolumn{2}{|l|}{213} \\
\hline $\mathrm{K}$ & Professional & 0 & & \multicolumn{2}{|l|}{0} & 0 & & \multicolumn{2}{|l|}{0} \\
\hline $\mathrm{L}$ & $\begin{array}{l}\text { Productive person } \\
\text { years }=\mathrm{F}+\mathrm{H}+\mathrm{I}+\mathrm{J}+\mathrm{K}\end{array}$ & 91 & & \multicolumn{2}{|l|}{207} & 134 & & \multicolumn{2}{|l|}{477} \\
\hline
\end{tabular}

divided into whether they have utilized their time productively or not. Now these sub branches terminate into 'Terminal node' $(\Delta)$. At each terminal node cost payoffs and effect payoffs were filled up by using the data from Tables 1 and 2. The values of the probabilities of each subgroup were filled up. Value of 'willingness to pay threshold' was put as Rs.15000/-. Now the tree was ready for roll back. This was shown in Figure 2.

In Figure 2 at each node (decision node, chance node and terminal node) the value of cost effectiveness is shown. The format used is Rs. $x$ required for $n$ amount of effectiveness. Decision analysis tree calculates the values at the terminal node. Then folds back to give values at the chance node and then at the decision node. At the end it suggests which strategy is cost effective under certain assumptions. It doesn't calculate individual person's costs or effectiveness. At 'Willingness to pay' (WTP) of Rs.15000/- to participate in the Second honeymoon programme was a cost-effective option. Cost for participation in programme was Rs. 965888 per 268 person years of productivity. Cost of not participating in the Second honeymoon programme but availing routine family planning services was Rs. 298902 per 133 person years gained. If value of WTP was reduced to below Rs. 5,000/-, not to participate in the second honeymoon programme became a cost-effective proposition. (Given all the remaining probabilities and payoffs constant)

Uncertainty is omnipresent in economic analyses, it might be in estimation of costs, in probabilities of success or valuing of outcomes. As a companion to statistical analysis, it was prudent to perform a sensitivity analysis. At the chance node 'participated in programme' there were two branches one is 'succeeded' and other branch is 'failed' (could not postpone pregnancy by two years). At the sub branch 'succeeded'; instead of quoting a constant probability of 0.514 , we inserted a variable named 'success'. At the sub branch 'failed' the complementary probability (total should be unity at each time) '\#' was entered.

At the eligible female participants branch; there were two sub branches. One was 'utilized time productively' branch and other was 'not utilized time productively' branch. We substituted the constant (probability 0.574 ) by a variable in the former branch. This variable was named as 'productive'. At the other branch 'not utilized time productively' branch complementary probability '\#' was entered. Our tree was ready for sensitivity analysis.

Rankings analysis showed that no strategies were clearly dominated by any other. Extended dominance report indicates no strategies were eliminated by extended dominance. Incremental costeffectiveness ratio was Rs.4920/- per person year of productivity. This means that incremental cost of Rs.4920/- is required for each incremental year of productivity. Dominance means the other programme was less costly and more effective than the comparator. Dominance report showed that no strategy was clearly dominated by the other strategy. This means that 'Second honeymoon programme' was not less costly and more effective than the 'family welfare programme'.

Table 3 shows the one way sensitivity analysis according to variable 'Success'. That was the probability of postponement of pregnancy in participants. First column showed the probability of success. It ranged from 0.01 to 0.99 . The cost and effectiveness was shown for both the strategies a. Not participated and b. Participated at each value of probability. In columns $4^{\text {th }}$ and $6^{\text {th }}$ 


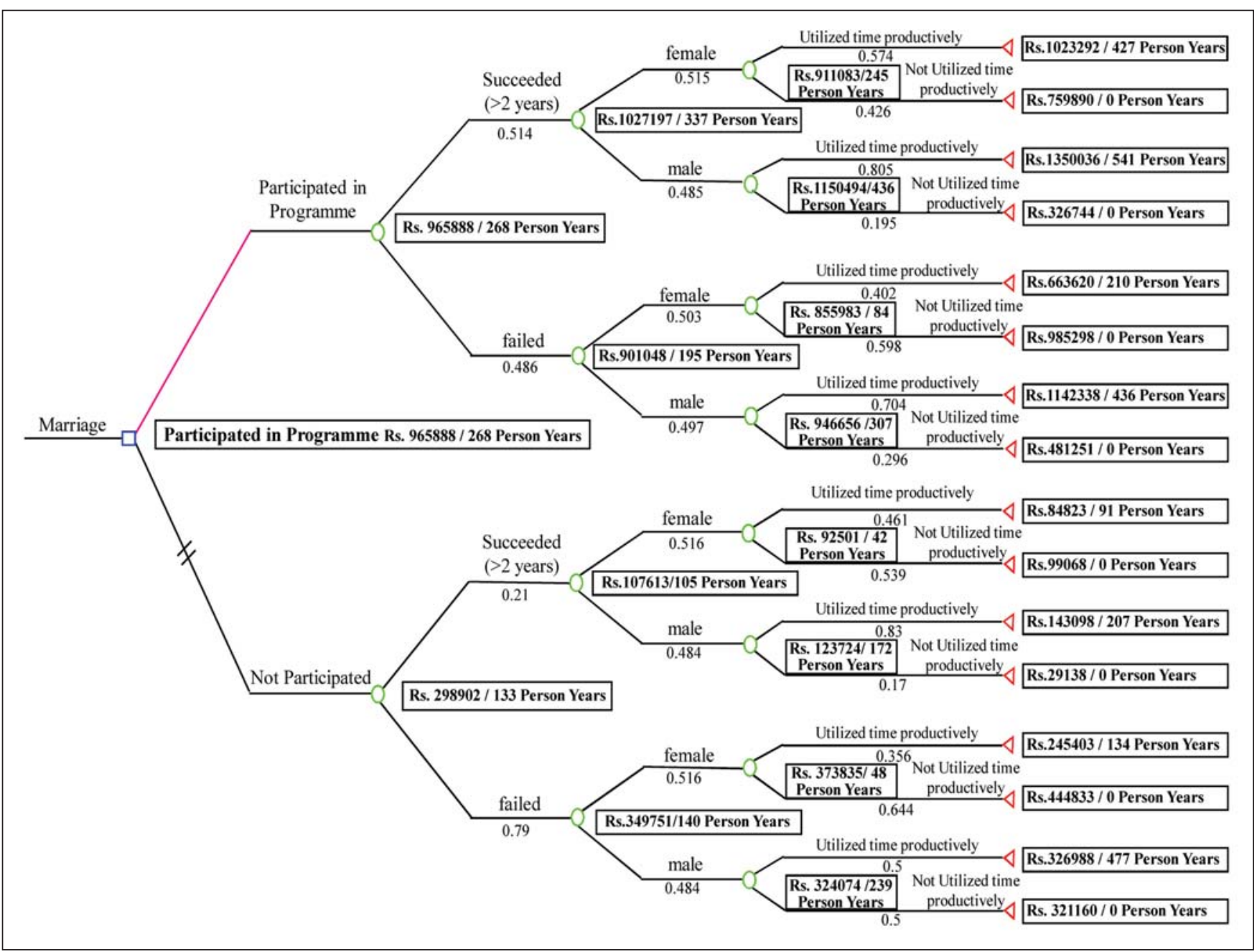

Figure 2: Decision tree rolled back

\begin{tabular}{|c|c|c|c|c|c|c|c|}
\hline P(success) & Strategy & Cost & $\begin{array}{c}\text { Incremental } \\
\text { cost }\end{array}$ & Effectiveness & $\begin{array}{l}\text { Incremental } \\
\text { effectiveness }\end{array}$ & C/E & $\begin{array}{c}\text { Incremental } \\
\text { C/E (ICER) }\end{array}$ \\
\hline \multirow[t]{2}{*}{0.01} & Not participated & Rs. 298902 & & 133 person years & & $\begin{array}{c}2253 \text { Rs. / } \\
\text { person-year }\end{array}$ & \\
\hline & $\begin{array}{l}\text { participated in } \\
\text { programme }\end{array}$ & Rs. 902309 & Rs. 603407 & 196 person years & 64 person years & $\begin{array}{l}4593 \text { Rs. / } \\
\text { person-year }\end{array}$ & $\begin{array}{c}9459 \text { Rs. /person- } \\
\text { year }\end{array}$ \\
\hline \multirow[t]{2}{*}{0.402} & Not participated & Rs. 298902 & & 133 person years & & $\begin{array}{c}2253 \text { Rs. / } \\
\text { person-year }\end{array}$ & \\
\hline & $\begin{array}{l}\text { participated in } \\
\text { programme }\end{array}$ & Rs. 951760 & Rs. 652858 & 252 person years & 120 person years & $\begin{array}{l}3773 \text { Rs. / } \\
\text { person-year }\end{array}$ & $\begin{array}{c}5458 \text { Rs. /person- } \\
\text { year }\end{array}$ \\
\hline \multirow[t]{2}{*}{0.598} & Not participated & Rs. 298902 & & 133 person years & & $\begin{array}{c}2253 \text { Rs. / } \\
\text { person-year }\end{array}$ & \\
\hline & $\begin{array}{l}\text { participated in } \\
\text { programme }\end{array}$ & Rs. 976485 & Rs. 677583 & 280 person years & 148 person years & $\begin{array}{l}3485 \text { Rs. / } \\
\text { person-year }\end{array}$ & $\begin{array}{c}4593 \text { Rs. /person- } \\
\text { year }\end{array}$ \\
\hline \multirow[t]{2}{*}{0.99} & Not participated & Rs. 298902 & & 133 person years & & $\begin{array}{c}2253 \text { Rs. / } \\
\text { person-year }\end{array}$ & \\
\hline & $\begin{array}{l}\text { participated in } \\
\text { programme }\end{array}$ & Rs. 1025936 & Rs. 727034 & 336 person years & 203 person years & $\begin{array}{l}3053 \text { Rs. / } \\
\text { person-year }\end{array}$ & $\begin{array}{c}3575 \text { Rs. /person- } \\
\text { year }\end{array}$ \\
\hline
\end{tabular}

incremental cost and incremental effectiveness was calculated. Average cost effectiveness was given in column seven. The last column showed the incremental cost effectiveness ratio (ICER). At probability of success of 0.01 the ICER was Rs. 9459/person 
year. As the probability increased to 0.206 , the incremental cost required for incremental person-year of achievement reduced to Rs.6849/-. When probability of success increased to 0.40 then ICER became Rs. 5458/person year. Similarly; when probability of success approached 0.99 , the incremental cost required for each person year became Rs.3575/-. So it can be inferred that as the probability of 'postponement of child birth by more than two years' (henceforth called as success) increases the incremental cost required for a unit of effectiveness decreases. That means incremental cost effectiveness ratio (ICER) declines. That means programme became more and more cost-effective as probability of success increased.

Table 4 shows one way sensitivity analysis according to the variable 'utilized time productively' by the female participants who were eligible for prize (means postponed childbirth by more than two years). In the first column, the variable 'productive' took values ranging from 0.01 to 0.99 . That means only $1 \%$ of persons utilized their time productively (Worst case scenario) then the incremental cost was Rs. 8739 per incremental person year. As more and more people used their time productively (that means the probability increases) then the incremental cost required for achieving incremental person-year decreased. As the probability of utilizing the time productively increases, the ICER decreases. When 99\% participants used their time productively (Best case scenario), the ICER will be reduced to Rs. 3812/person-year. This means as more and more participants utilized their time productively then this programme became more cost effective.

A two-way sensitivity analysis identifies the optimal alternative for each combination of values of the two variables. Based on this, a region graph was created in the two dimensional variable space with regions assigned to the alternatives based on their optimality. The curvy line dividing two regions was threshold line. For the given WTP, the strategy having the highest net benefit for any coordinate in the analysis was assigned that point. Regions of cost effectiveness were constructed on this basis. Figure 3 shows two way sensitivity analysis according to variables productive (probability of utilizing the time productively) and success (Probability of postponement of pregnancy). This figure shows net health benefits at willingness to pay threshold of Rs. 5500. One vertical line was drawn in the middle of the figure to show 0.45 probability of productivity and a horizontal line was drawn at 0.35 probability of success. So we can see that if more than $35 \%$ of participants succeed in postponing pregnancy by two years and more than $45 \%$ of them used their time productively then participating in the programme becomes a cost effective proposition.

Monte Carlo simulation took 1000 samples. Computer simulated 1000 odd experiments. (Studies) The results of all these random experiments were treated like a distribution. They were analysed to give the mean, standard deviation, percentile values, range and sum. Please refer to the Table 5.

Table 5 shows the Monte Carlo effectiveness statistics. First column specifies the type of statistics, Second column shows the cost of

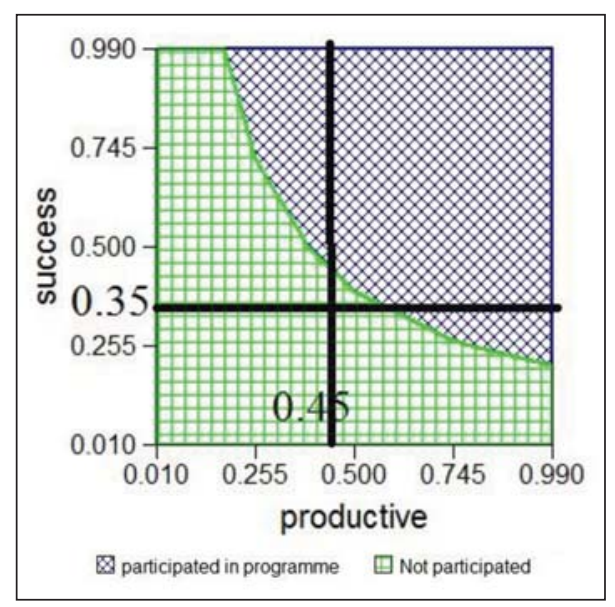

Figure 3: Two way sensitivity analysis

\begin{tabular}{|c|c|c|c|c|c|c|c|}
\hline $\mathrm{P}$ (productive) & Strategy & Cost & $\begin{array}{c}\text { Incremental } \\
\text { cost }\end{array}$ & Effectiveness & $\begin{array}{l}\text { Incremental } \\
\text { effectiveness }\end{array}$ & $\mathrm{C} / \mathrm{E}$ & $\begin{array}{c}\text { Incremental C/E } \\
\text { (ICER) }\end{array}$ \\
\hline \multirow[t]{2}{*}{0.01} & Not participated & Rs. 298902 & & 133 person years & & $\begin{array}{c}2253 \text { Rs. / } \\
\text { person-year }\end{array}$ & \\
\hline & $\begin{array}{l}\text { participated in } \\
\text { programme }\end{array}$ & Rs. 926564 & Rs. 627662 & 204 person years & 72 person years & $\begin{array}{l}4531 \text { Rs. / } \\
\text { person-year }\end{array}$ & 8739 Rs. /person-year \\
\hline \multirow[t]{2}{*}{0.402} & Not participated & Rs. 298902 & & 133 person years & & $\begin{array}{l}2253 \text { Rs. / } \\
\text { person-year }\end{array}$ & \\
\hline & $\begin{array}{l}\text { participated in } \\
\text { programme }\end{array}$ & Rs. 953896 & Rs. 654994 & 249 person years & 116 person years & $\begin{array}{l}3834 \text { Rs. / } \\
\text { person-year }\end{array}$ & 5640 Rs. /person-year \\
\hline \multirow[t]{2}{*}{0.598} & Not participated & Rs. 298902 & & 133 person years & & $\begin{array}{l}2253 \text { Rs. / } \\
\text { person-year }\end{array}$ & \\
\hline & $\begin{array}{l}\text { participated in } \\
\text { programme }\end{array}$ & Rs. 967562 & Rs. 668660 & 271 person years & 138 person years & $\begin{array}{l}3571 \text { Rs. / } \\
\text { person-year }\end{array}$ & 4835 Rs. /person-year \\
\hline \multirow[t]{2}{*}{0.99} & Not participated & Rs. 298902 & & 133 person years & & $\begin{array}{c}2253 \text { Rs. / } \\
\text { person-year }\end{array}$ & \\
\hline & $\begin{array}{l}\text { participated in } \\
\text { programme }\end{array}$ & Rs. 994894 & Rs. 695992 & 315 person years & 183 person years & $\begin{array}{l}3156 \text { Rs. / } \\
\text { person-year }\end{array}$ & 3812 Rs. /person-year \\
\hline
\end{tabular}




\begin{tabular}{|c|c|c|c|c|c|c|}
\hline Statistic & $\begin{array}{c}\text { Cost } \\
\text { (participated in } \\
\text { programme) }\end{array}$ & $\begin{array}{l}\text { Effectiveness } \\
\text { (participated in } \\
\text { programme) }\end{array}$ & $\begin{array}{c}\mathrm{C} / \mathrm{E} \text { (participated in } \\
\text { programme) }\end{array}$ & $\begin{array}{c}\text { Cost (Not } \\
\text { participated) }\end{array}$ & $\begin{array}{c}\text { Effectiveness } \\
\text { (Not participated) }\end{array}$ & $\begin{array}{c}\text { C/E (Not } \\
\text { participated) }\end{array}$ \\
\hline Mean & Rs. 960757 & 259 person years & & Rs. 305801 & 125 person years & \\
\hline Standard Deviation & Rs. 297890 & 230 person years & -1 Rs. /person-year & Rs. 115738 & 179 person years & -1 Rs/person-year \\
\hline Minimum & Rs. 326744 & 0 person years & 2396 Rs/person-year & Rs. 29138 & 0 person years & 686 Rs/person-year \\
\hline $2.50 \%$ & Rs. 326744 & 0 person years & 2396 Rs/person-year & Rs. 84823 & 0 person years & 686 Rs/person-year \\
\hline $10 \%$ & Rs. 481251 & 0 person years & 2396 Rs/person-year & Rs. 99068 & 0 person years & 686 Rs/person-year \\
\hline Median & Rs. 1023292 & 427 person years & 2620 Rs/person-year & Rs. 321160 & 0 person years & \\
\hline $90 \%$ & Rs. 1350036 & 541 person years & & Rs. 444833 & 477 person years & \\
\hline $97.50 \%$ & Rs. 1350036 & 541 person years & & Rs. 444833 & 477 person years & \\
\hline Maximum & Rs. 1350036 & 541 person years & & Rs. 444833 & 477 person years & \\
\hline Sum (n*mean) & Rs. 960756659 & $\begin{array}{c}258705 \text { person } \\
\text { years }\end{array}$ & & Rs. 305801300 & $\begin{array}{c}125492 \text { person } \\
\text { years }\end{array}$ & \\
\hline
\end{tabular}

\begin{tabular}{|c|c|c|c|c|c|c|}
\hline Component & Quadrant & $\begin{array}{l}\text { Incr. } \\
\text { eff. }\end{array}$ & $\begin{array}{l}\text { Incr. } \\
\text { cost }\end{array}$ & ICER & $\begin{array}{c}\# \\
\text { points }\end{array}$ & $\begin{array}{c}\text { Percent } \\
\text { (\%) }\end{array}$ \\
\hline $\mathrm{C} 1$ & IV & $\mathrm{IE}>0$ & $\mathrm{IC}<0$ & Superior & 0 & 0 \\
\hline $\mathrm{C} 2$ & I & $I E>0$ & $I C>0$ & $<15000$ & 428 & 42.80 \\
\hline $\mathrm{C} 3$ & III & $\mathrm{IE}<0$ & $\mathrm{IC}<0$ & $>15000$ & 0 & 0 \\
\hline C4 & I & $I E>0$ & $I C>0$ & $>15000$ & 72 & 7.20 \\
\hline C5 & III & $\mathrm{IE}<0$ & $\mathrm{IC}<0$ & $<15000$ & 0 & 0 \\
\hline C6 & II & $\mathrm{IE}<0$ & $I C>0$ & Inferior & 500 & 50 \\
\hline Indifference & origin & $\mathrm{IE}=0$ & $\mathrm{IC}=0$ & $0 / 0$ & 0 & 0 \\
\hline
\end{tabular}

participation in the programme, third column shows person-years gained by participating in programme. Next column shows cost effectiveness of participation. Fifth column shows the cost incurred for those persons who have not participated in programme. Sixth column shows the person-years gained without participating in Second honeymoon package programme. Last column shows cost effectiveness ratio for those who have not participated. Here the mean cost of participation was Rs. 960757/- with a standard deviation (SD) of Rs. 297890. Mean person-years gained by participants are 259 with SD of 230. Cost effectiveness of participation ranged from - 1000 to 2620 Rs. / person-year. Mean cost for controls was Rs. 305801 with SD of Rs. 115738. Mean person-years gained by controls was 125 with SD of 179. Cost effectiveness ratio of non-participation ranged from -1000 to 686 Rs. / person-years.

Incremental cost effectiveness (ICE) scatterplot uses a form of standard cost effectiveness (CE) plane to plot points for each iteration in the simulation report. The ICE scatterplot includes single set points representing pairs of incremental cost and effectiveness values from the simulation results based on a comparator relative to a baseline. The points in the scatterplot represent the comparator's incremental cost and incremental effectiveness relative to a baseline. (Represented by the origin) The willingness to pay (WTP) or ceiling ICER is used as the slope of the line intersecting the origin of the plot. The WTP line in the graph intersects points having the specified ICER value; the region below the line includes cost-effective points. This was utilized in the scatterplot's text report to calculate the percentage of simulation iterations for which the comparator is cost effective.

Table 6 shows that in $\mathbf{4 2 . 8} \%$ of iterations; Second honeymoon programme was more costly but lies below the WTP. That means affordable at predetermined price point. In $50 \%$ of simulation experiments SHP was inferior to its comparator, i.e. National family welfare programme. In $7.2 \%$ of experiments, SHP was more costly and lies above WTP $=10000$, means not affordable at that price point.

\section{DISCUSSION}

Reaching married adolescents can be cost efficient, may be introduced at scale and is sometimes less controversial than introducing programmes for unmarried youth. In countries, that have a strong family planning infrastructure, reorienting the programme to reach married adolescents may be achieved with minimal inputs. In Bangladesh, Pathfinder has found that reorienting family planning workers to conduct outreach work to serve married adolescents would be required minimal additional resources. The strategy could be brought to scale quickly by grafting services for newly weds onto already-existing family planning programs, achieving broad coverage of newlywed couples within a few years of programme initiation. ${ }^{[2]}$ Mavranezouli I has conducted cost effectiveness analysis of long acting reversible contraceptive (LARC) methods in the UK. He has compared LARC with oral contraceptive pills and female sterilization for the prevention of pregnancy. The four LARC methods have been Copper T, Levonorgestrel intra uterine system, etonorgestrel and depot medroxy progesterone acetate injection. They have found that all LARC methods dominated the Oral contraceptive pills. In the Second honeymoon package programme, LARC methods have not been offered to the participants. These methods should be incorporated in our programme in future. ${ }^{[3]}$

Nakhaee et al., have assessed the cost effectiveness of contraceptive methods in Shiraz, Islamic republic of Iran. They have examined oral contraceptives, male condoms, injectable contraceptives and intra uterine devices. Effectiveness has been measured in terms of 
conventional couple years of protection (CYP). The have estimated total costs have been $\$ 238330$ with oral contraceptives (385 users), $\$ 490676$ with male condoms (385 users), and \$289772 with copper $T$ (1100 users). They have concluded that male condoms turned out to be the most expensive strategy, while contraceptive implants represented the least costly method of contraception. In the present study the most frequently used method is male condoms. ${ }^{[4]}$ Trussell et al., have conducted cost utility analysis of contraceptives in the United States. Their study has examined cost effectiveness of various female and male contraceptive strategies compared with no contraception in the general population. Over 5 years the total costs have been $\$ 647$ with copper T, $\$ 1575$ with male condom, $\$ 3381$ with oral contraceptives and $\$ 4739$ with no method. They have concluded that all the contraceptive strategies have been more effective and less costly than no method. ${ }^{[5]}$ This finding differs from that in our study. In our study the comparator has been the well managed and top priority national health programme 'National family welfare programme'. We have not compared SHP with "do nothing" strategy. Therefore SHP has not been found to be dominant over its comparator.

Chiou et al., have conducted economic analysis of contraceptives for women in the United States, from the health care services payer's perspective (third party payer). Levonorgestrel- 20 Intra Uterine System and Copper T 380-A have dominated all reviewed methods. The 5 years cost per person has been $\$ 1646$ for Levonorgestrel, \$ 1678 for Copper T 380 A and \$2195 for 3 monthly injectable contraceptives. This gives annual cost range of \$329- 439 per person. This is quite costly than those in the present study, which ranges from $\$ 15$ to 29 per person per year. This may because of exorbitantly costly health system based on health insurance in USA. $^{[6]}$

\section{CONCLUSIONS}

The present study has found that incremental cost for participating in 'Second honeymoon package' programme has been Rs. 666987/-. The incremental effectiveness has been 136 productive person-years. This gives the incremental cost effectiveness ratio of Rs. 4920/ person-year. The SHP is cost effective at high success and productivity rates. The minimum success rate of postponement of first pregnancy required for cost effective implementation of SHP was $35 \%$ while minimum probability of productive utilization of time was $45 \%$ for SHP to be cost effective. In the present study, probability of success has been 0.514 and probability of productivity of 0.574 is well above the minimum level hence the model is replicable. To make the model more acceptable, efficacious and cost effective favorable factors need to be enhanced (like availability of vocational training schools, job opportunities and better access), at the same time hindering factors need to be diminished. (e.g. too much paperwork, indifferent attitude of health workers to approach the couples etc.). Using Monte Carlo simulation and incremental cost effectiveness scatterplot confidence interval has been worked out. $50 \%$ superiority and $42.8 \%$ affordability of SHP, which again can be improved by modifying and revamping the programme to improve the probability of success and productivity by aforementioned measures without adding cost inputs.

\section{REFERENCES}

1. Drummond MF, Sculpher MJ, Torrance GW, O'Brien BJ, Stoddart GL. Methods for the Economic Evaluation of Health Care Programmes. Third edition. Oxford University Press; New York, 2005:39-43.

2. Alauddin M, MacLaren L. FHI 360 - Reaching Newlywed and Married Adolescents [Internet]. 1999. Available from: http://www.fhi360.org/en/ Youth/YouthNet/Publications/FOCUS/InFOCUS/newlywedandmarried. htm [Last cited 2012 Oct 2].

3. Mavranezouli I. The cost-effectiveness of long-acting reversible contraceptive methods in the UK: Analysis based on a decision-analytic model developed for a National Institute for Health and Clinical Excellence (NICE) clinical practice guideline. Hum Reprod 2008;23:1338-45.

4. Nakhaee N, Mirahmadizadeh AR, Gorji HA, Mohammadi M. Assessing the cost-effectiveness of contraceptive methods in Shiraz, Islamic Republic of Iran. East Mediterr Health J 2002;8:55-63.

5. Trussell J, Leveque JA, Koenig JD, London R, Borden S, Henneberry J, et al. The economic value of contraception: A comparison of 15 methods. Am J Public Health 1995;85:494-503.

6. Chiou CF, Trussell J, Reyes E, Knight K, Wallace J, Udani J, et al. Economic analysis of contraceptives for women. Contraception 2003;68:3-10.

How to cite this article: Pratinidhi AK, Lale SV. Economic evaluation of conditional cash transfer scheme for postponement of first pregnancy in newly married couples in Satara district of Maharashtra (India). Int J Med Public Health 2013;3:278-85.

Source of Support: Nil, Conflict of Interest: None declared. 